\title{
Uma reflexão sobre tecnologias inovadoras aplicadas à mobilidade urbana sustentável
}

A reflection on innovative technologies for sustainable urban mobility

\author{
Maria Fernanda Kauling ${ }^{47}$ \\ Clarissa de Oliveira Cavalcanti ${ }^{48}$ \\ Marcelo Limont ${ }^{49}$ \\ Valdir Fernandes ${ }^{50}$
}

Artigo recebido para publicação em Set./2014 e aceito para publicação em Set./2014.

\begin{abstract}
RESUMO
As aglomerações populacionais ocorridas nos centros urbanos brasileiros nas últimas décadas desconfiguram o papel das cidades e promovem a desarmonia entre as dimensões do desenvolvimento sustentável. Esta situação demanda atenção à dimensão política da sustentabilidade, de forma a direcionar o planejamento urbano ao atingimento de metas sociais, à eficiência econômica da aplicação dos recursos e à utilização racional dos recursos naturais. Neste contexto, a mobilidade urbana está diretamente relacionada ao alcance da população às oportunidades de trabalho e estudo, pois refletem as condições de deslocamento no espaço urbano, com impacto direto na qualidade de vida. Um dos critérios para a concepção de um sistema de mobilidade urbana é a adoção de tecnologias inovadoras. Dessa forma, o objetivo deste ensaio é estimular a reflexão sobre as possibilidades e contribuições da tecnologia à sustentabilidade urbana, especialmente sob os aspectos relativos à mobilidade urbana sustentável.
\end{abstract}

Palavras-chave: Mobilidade urbana sustentável. Tecnologias inovadoras. Desenvolvimento sustentável.

\section{ABSTRACT}

The population agglomerations occurred in Brazilian urban centers in recent decades came harm the role of cities and promote disharmony between the dimensions of sustainable development. This demands attention to the political dimension of sustainability in order to direct the urban planning to the achievement of social goals, the economic efficiency of the application of resources and the rational use of natural resources. In this context, the urban mobility is directly related to the population to opportunities for work and study, they reflect the conditions of displacement in urban areas, with direct impact on quality of life. One of the criteria for the design of a system of urban mobility is the adoption of innovative technologies. Thus, the purpose of this essay is to stimulate reflection on the possibilities and contributions of technology to urban sustainability, especially under the aspects of sustainable urban mobility.

Keywords: Sustainable urban mobility. Innovative Technologies. Sustainable development.

\footnotetext{
${ }^{47}$ Advogada, Especialista em Direito Processual Civil. Mestranda no Programa de Pós-Graduação em Gestão Ambiental da Universidade Positivo.E-mail: mariakauling@hotmail.com.

48 Engenheira civil. Mestranda no Programa de Pós-Graduação em Gestão Ambiental da Universidade Positivo. E-mail: clacavalcanti@hotmail.com.

49 Licenciado em Biologia, Doutor em Meio Ambiente e Desenvolvimento. Pós-doutorando no Programa de Pós-Graduação em Gestão Ambiental da Universidade Positivo. E-mail: marcelobio@yahoo.com.br.

${ }^{50}$ Cientista Social, Doutor em Engenharia Ambiental. Professor dos Programas de Pós-Graduação em Gestão Ambiental da Universidade Positivo e, Governança e Sustentabilidade do ISAE/FGV. E-mail: valdir.fernandes@icloud.com.
} 


\section{INTRODUÇÃO}

Crescimento populacional, industrialização, urbanização e tecnologia são algumas características que marcam o processo civilizatório das sociedades contemporâneas. Concomitantemente, degradação e escassez dos recursos naturais, pobreza e desigualdades sociais estão intrinsecamente associadas e assim delimitam o cenário histórico do desenvolvimento mundial.

No período pós-guerra, a construção de um modelo de desenvolvimento baseado na força do capital econômico desenhou um panorama global fortemente relacionado ao fomento industrial e tecnológico, com padrões elevados de consumo que garantiram a emergência da economia e seus benefícios sociais. Em consequência, instalou-se gradativamente uma crise desse modelo, marcada pela saturação dos mercados, depleção da base material dos recursos naturais, custos sociais de produção elevados e diminuição nos investimentos de capital (GASPAR, 2011).

Em paralelo, se evidencia cada vez mais um conjunto de desigualdades sociais relacionadas à distribuição de renda e deficiência na atenção às necessidades básicas da população. Veiga (2005) aponta que a erradicação da pobreza, a adequada distribuição de renda e o atendimento aos serviços de saúde, educação e saneamento básico, por exemplo, são dimensões que estiveram ausentes no conceito de desenvolvimento econômico dominante.

Dirimir tais externalidades sociais e ambientais inerentes ao processo produtivo passa a nortear proposições de desenvolvimento que transcendem o objetivo único de maximização dos lucros. Para tanto, Furtado (1996) defendia a necessidade de uma mudança estrutural na perspectiva de um conceito de desenvolvimento como elemento transformador na relação e nas proporções internas do sistema econômico. Assim, tal conceito não devia somente estar relacionado a índices como o Produto Interno Bruto (PIB) ou distribuição da renda per capita.

Surge, portanto, a necessidade de se buscar novos processos produtivos e tecnológicos que consigam, minimamente, agregar a adjetivação da sustentabilidade ao conceito de desenvolvimento, declarando uma tentativa de se traçar um novo paradigma econômico que considere o impacto sobre os recursos naturais na mesma medida em que garanta justiça social.

Para Bossel (1999), o sistema econômico construído é injusto e será socialmente insustentável enquanto favorecer relações sociais desiguais. Furtado 
(1996) sugeria que não se poderia tentar alcançar os índices de desenvolvimento econômico nos países periféricos tendo como referência os parâmetros dos países centrais. Por consequência, a pressão sobre os recursos naturais e a poluição inerente ao processo produtivo "seriam de tal ordem (ou, alternativamente, o custo do controle da poluição seria tão elevado) que o sistema econômico mundial entraria necessariamente em colapso" (FURTADO, 1996, p. 11).

Este conceito de desenvolvimento fundamentado apenas no processo de industrialização e no crescimento econômico tem sido amplamente questionado desde a década de 1970, dentre outros por autores como Furtado (1989, 1996 e 2002), Polanyi (1994, 2000), Sachs (2000, 2012), Sen (2000) e Max-Neef (1993). Como alternativa surge, na década de 1980, o conceito de desenvolvimento sustentável, sendo "aquele que atende às necessidades do presente sem comprometer a possibilidade de as gerações futuras atenderem as suas próprias necessidades" (COMISSÃO MUNDIAL SOBRE MEIO AMBIENTE E DESENVOLVIMENTO, 1991, p. 46). Trata-se de uma definição que remete a uma visão de mundo, um paradigma no qual é defendida a integração de diversas dimensões do desenvolvimento (ambiental, social, política e econômica). Um conceito que remete a uma responsabilidade intergeracional, cujo maior desafio é produzir um desenvolvimento menos associado às noções de mais (+) e de menos (-), e mais associado à noção de suficiente (FERNANDES, 2008).

$\mathrm{Na}$ esteira da complexidade das temáticas envolvidas na conceituação de desenvolvimento sustentável, Meadows (1998) reforça um grande elemento ambiental necessário à vida humana, o bem estar. A eficiência com que os recursos ambientais se transformam em bem estar e a capacidade de suporte no uso destes recursos se traduzem em medida básica de desenvolvimento sustentável.

Neste contexto histórico, a tecnologia exerceu papel central no processo de industrialização, contribuindo sobremaneira na sedimentação e reprodução do modelo de desenvolvimento econômico hegemônico. De acordo com Weber (1996), o capitalismo é resultado de uma moderna organização racional viabilizada, sobretudo, pela separação entre empresa e economia doméstica e pela criação da contabilidade racional, associadas ao desenvolvimento das possibilidades técnicas e tecnológicas (FERNANDES, 2008).

Atualmente, ela vem sendo desafiada a questionar tal modelo a ponto de transformar sua estrutura, tornando-se, mais uma vez, elemento fundamental do desenvolvimento, só que agora em uma perspectiva ampliada. 
Amparado no processo industrial, o desenvolvimento tecnológico surge como referência de transformação social. Inovações tecnológicas são percebidas como caminhos possíveis de se superar os dilemas da relação entre conservação ambiental e crescimento econômico (SOLOW, 2000). Assim, questionar o padrão de produção e consumo em meio ao processo de desenvolvimento também é papel atribuído à tecnologia.

Polanyi (2000) já previa, diante do processo industrial europeu que se iniciou no fim do século IX, princípios de comportamento capazes de assegurar a ordem na produção e distribuição sem que a motivação econômica seja a grande mola propulsora do mecanismo industrial: reciprocidade e redistribuição. $\mathrm{O}$ autor defende que o sistema econômico é mera função da organização social. Cabe, portanto, às organizações sociais atuais priorizarem seus valores e as estruturas institucionais que querem fazer valer em seus territórios.

No contexto deste ensaio e na tentativa de aproximar essa discussão teórica de um recorte temático, nos apropriamos de duas características apresentadas anteriormente e que marcaram o desenvolvimento das sociedades contemporâneas, a saber, a industrialização e o processo de urbanização. Estimular a reflexão sobre as possibilidades e contribuições da tecnologia à sustentabilidade urbana é objetivo subsequente, especialmente sob aspectos relacionados à mobilidade urbana sustentável.

\section{URBANIZAÇÃO, INDUSTRIALIZAÇÃO E A TECNOLOGIA}

Um dos efeitos considerados mais significativos do movimento industrial é o adensamento dos espaços urbanos que, frequentemente, se forma em torno dos parques industriais. $O$ aumento populacional pode ser considerado como maior impacto ambiental causado pela implementação de grandes empreendimentos (TAVARES, 2005).

O modelo fordista de produção, ainda seguido pelos parques industriais brasileiros, traz consigo situações que precisam ser enfrentadas quando o objetivo é erradicar a pobreza pelo fomento ao crescimento. Bolsões de pobreza, degradação ambiental, infraestrutura básica precária e incidência de desempregados, são exemplos de situações que desqualificam o crescimento trazido pela indústria (TAVARES, 2005). 
A herança do período colonial que acirrou as desigualdades sociais, segundo Gaspar (2011), é reproduzida nos espaços urbanos, corroborando na concentração de pessoas e recursos em metrópoles e criando faixas territoriais seletivas. Identificam-se nesse movimento, dois fenômenos distintos, porém interligados: a urbanização e a metropolização.

O esvaziamento do espaço rural por conta da concentração de incentivos de recursos e renda nas áreas urbanas caracteriza fator imperativo no debate ambiental mundial. Em 1960, 34\% da população mundial vivia em centros urbanos. Em 2011 esse percentual subiu para $82 \%$ na América do Norte, $80 \%$ na América Latina e Caribe, $73 \%$ na Europa, $70 \%$ na Oceania, $42 \%$ na Ásia e $40 \%$ na África (ORGANIZAÇÃO DAS NAÇÕES UNIDAS, 2011). 36\% da população brasileira moravam nas cidades em 1950, em 2010 a proporção urbana passou para $84 \%$ (INSTITUTO BRASILEIRO DE GEOGRAFIA E ESTATÍSTICA, 2010).

O impacto geográfico e na territorialidade gerado pela economia industrial urbana é iminente. No contexto brasileiro, ocorre o processo de transformação do Brasil agrário para o Brasil industrial. Percebe-se um desenho de crescimento populacional nas regiões sul e sudeste do país destoante de outras regiões, causando fortes desequilíbrios sociais e regionais (ROMANELLI; ABIKO, 2011).

$O$ adensamento populacional no território urbano vai causando uma ocupação periférica natural, já que os espaços centrais ganham projeção e valorização mobiliária. Reproduz-se o modelo de organização do espaço na delimitação de centro e periferia. $O$ centro concentra as principais atividades econômicas, públicas ou privadas, as infraestruturas urbanas e as áreas habitacionais de mais alto nível de renda. A periferia, em torno dos parques industriais, alimentada por invasões, loteamentos populares, serve para abrigar a população de baixa renda. (ROMANELLI; ABIKO, 2011).

As metrópoles surgem como reprodução de um sistema planetário, com desafios semelhantes aos apontados por Meadows em 1972. Num espectro urbano e regional, a coletividade induz a maior individualização e diversificação nas relações sociais na vida urbana (GASPAR, 2011).

Segundos Santos (1994), a partir das décadas de 1940 e 1950, houve a mudança da base econômica do país, que antes fundada na agricultura, passa à industrialização, com a formação de um mercado nacional, a expansão do consumo em formas diversas e a ativação do processo de urbanização, que se tornou cada vez mais envolvente e presente no território brasileiro. 
Como não houve um controle ordenado desta situação, os territórios urbanos não estavam preparados para receber o contingente populacional, e com diferença de grau e de intensidade, todas as cidades brasileiras passaram a apresentar dificuldades semelhantes em relação às temáticas de saneamento básico, educação, saúde, lazer, habitação e transporte. As dimensões destes problemas são proporcionais ao tamanho das cidades, o que é agravado por investimentos públicos que não priorizam gastos sociais (SANTOS, 1994).

Estas dificuldades evidenciam a necessidade do planejamento urbano ser permeado pelo conceito de desenvolvimento sustentável na totalidade da sua dimensão territorial. Neste sentido, Sachs (2012), enfatiza que o planejamento deve identificar metas sociais ambiciosas, porém viáveis, com a proposição de padrões eficientes de utilização de recursos.

Para Sassen $(2001,2006,2007)$ os aglomerados urbanos se caracterizam por concentrar os setores mais dinâmicos da economia, os modernos serviços produtivos e financeiros. Um exemplo é o setor de transporte urbano, que corrobora o conceito de mobilidade urbana e que será abordado no item subsequente à luz das tecnologias inovadoras em sistemas de transporte.

Os investimentos realizados em transporte, em geral, viabilizam o fluxo de veículos motorizados e ao invés de proporcionar qualidade de vida e de circulação, intensificam os conflitos entre os diferentes modos de deslocamento (DUARTE; LIBARDI; SÁNCHEZ, 2009). Isso favorece a desarmonia entre as dimensões social, econômica e ambiental da sustentabilidade.

Um dos instrumentos apontados para retomar esta harmonização é, novamente, o planejamento urbano que, segundo Duarte, Libardi e Sánchez (2009), não é exclusivo ao desenvolvimento de uma política de mobilidade. Todavia também deve incorporar o conceito de sustentabilidade, com o intuito de incentivar o uso do transporte coletivo e dos modos não motorizados de transporte de maneira efetiva, socialmente inclusiva e ecologicamente sustentável. Essa mobilidade é constituída de todos os modais de transporte e suas inter-relações, como a articulação entre o uso do solo, planejamento urbano e qualidade ambiental.

Neste sentido, Nicolas e Jourmard (2010) propuseram critérios para orientar a avaliação de projetos de transporte urbano e que aqui, podem ser percebidos como aspectos a serem considerados e que podem contribuir com a perspectiva da sustentabilidade urbana. Os autores consideram quatro dimensões: (i) econômica: considerando vantagens econômicas para comunidade afetada pelo projeto, ganhos 
gerados com a indução do tráfego e geração de empregos pela construção da infraestrutura; (ii) social: acessibilidade aos serviços públicos, emprego e oportunidades que podem ser alcançadas utilizando um carro particular ou o transporte público e custo da mobilidade, e segurança dos moradores e usuários; (iii) ambiental: qualidade local e regional do ar; (iv) ambiental reversível: qualidade da água, manutenção da biodiversidade, riscos naturais e tecnológicos, emissões de gases de efeito estufa, perturbação acústica e poluição luminosa, alteração da paisagem, impermeabilização do solo e consumo de matérias-primas não renováveis.

\section{TECNOLOGIAS INOVADORAS EM SISTEMAS DE TRANSPORTE}

Os critérios propostos por Nicolas e Jourmard (2010) podem ser potencializados pela aplicação de outra diretriz considerada em avaliação de mobilidade urbana: a utilização de tecnologias inovadoras para melhoria da eficiência do transporte. Segundo Haque, Chin e Debnath (2013), a incorporação de tecnologias inovadoras no sistema de mobilidade urbana aumenta a eficiência e confiabilidade do sistema, melhora o conforto dos passageiros e ajuda a promover políticas de segurança e sustentabilidade.

Convergente ao estudo de Haque, Chin e Debnath (2013), Debnath et al. (2014) apresentam um conjunto de indicadores para avaliar a utilização de tecnologias inovadoras em diversas cidades do mundo, no qual afirma-se que a avaliação global de desempenho das cidades, quanto ao seu grau de inovação, deve não somente considerar a inovação do sistema de transporte urbano, mas também considerar a extensão do uso das inovações tecnológicas e os níveis desta inovação.

Segundo Giffinger, Haindlmaier e Kramar (2010, apud DEBNATH et al., 2014), Giffinger et al. (2007, apud DEBNATH et al., 2014), Lazaroiu e Roscia (2012, apud DEBNATH et al., 2014) e Lee, Phaal e Lee (2013 apud DEBNATH et al., 2014), uma cidade inovadora é caracterizada por sua infraestrutura em tecnologia de informação e comunicação, melhorando a inteligência, conectividade e sustentabilidade do sistema urbano.

Debnath et al. (2014) avaliaram cidades que dispusessem de um bom nível de infraestrutura em setores como transporte, distribuição de eletricidade, abastecimento de água e telecomunicações, e com população superior a dois 
milhões de habitantes. Estes autores também consideram que a utilização de tecnologias inovadoras é viável somente em cidades que tenham atendido uma condição mínima de infraestrutura básica, representada por aqueles setores.

Os indicadores utilizados nesta avaliação e considerados como "indicadores de transporte inovador" (DEBNATH et al., 2014, p. 52), foram aplicados aos subsistemas de transportes privado, público e de emergência, sendo os mais relevantes para as políticas de mobilidade urbana aqueles elencados no Quadro 1.

\section{Quadro 1 - Exemplos de indicadores de transporte inovador}

\begin{tabular}{|c|c|}
\hline Transporte privado & $\begin{array}{l}\text { Capacidade de: } \\
\text { - Detecção de veículos individuais e informações sobre o estado destes } \\
\text { (velocidade, ocupação, cobrança de pedágio, entre outras) pelo sistema } \\
\text { automático de reconhecimento de placas; } \\
\text { - Operação - controle automatizado e coordenado de sinalização de tráfego } \\
\text { (\% de intersecções cobertas com rede coordenadas de sinalização); } \\
\text { - Previsão de fluxo de tráfego - capaz de prever o fluxo de tráfego e } \\
\text { velocidade; } \\
\text { - Atendimento à demanda - capaz de prever a demanda e ajustar a oferta } \\
\text { (controle e ajuste de fluxo de veículos). }\end{array}$ \\
\hline Transporte público & $\begin{array}{l}\text { Capacidade de: } \\
\text { - Detecção em rota - capaz de detectar veículo individual em trânsito (\% de } \\
\text { onibus públicos e táxis equipados com sistema automático de localização } \\
\text { de veículos - GPS); } \\
\text { - Detecção de passageiros - capaz de detectar passageiro individual } \\
\text { (existência de sistema centralizado que permite rastrear os movimentos } \\
\text { dos passageiros por meio de seus cartões inteligentes; } \\
\text { - Operação - capaz de oferecer prioridade (ao transporte público) nos sinais } \\
\text { de trânsito (porcentagem de intersecções com sistema de sinalização } \\
\text { automatizado de prioridade); } \\
\text { - Operação - capaz de operar o trânsito com redução da intervenção } \\
\text { humana (veículos com direção automática); } \\
\text { - Transação - cobrança de tarifa eletrônica e intermodal; } \\
\text { - Veículo - comunicação com o usuário - gestão de informações ao } \\
\text { passageiro (informações em tempo real para telefones celulares - } \\
\text { porcentagem de estações e paradas de ônibus que disponibilizam este } \\
\text { serviço). }\end{array}$ \\
\hline $\begin{array}{l}\text { Transporte } \\
\text { emergência }\end{array}$ & $\begin{array}{l}\text { Capacidade de: } \\
\text { - Operação - capaz de oferecer prioridade (aos veículos de emergência) nos } \\
\text { sinais de trânsito (porcentagem de intersecções com sistema de } \\
\text { sinalização automatizado de prioridade); } \\
\text { - Operação de veículos - comunicação com o motorista (fornecimento de } \\
\text { informacões em tempo real para os motoristas - conduta dinâmica). }\end{array}$ \\
\hline
\end{tabular}

Fonte: Debnath et al.,( 2014, p. 52).

Com base no estudo, as cinco cidades melhores avaliadas por Debnath et al. (2014) são Londres, Seattle, Sidney, Nova lorque e Melbourne, as quais possuem algumas características em comum: (i) tecnologias de rastreamento de veículos de emergência e de transporte público; (ii) sistema automático de localização de 
veículos a bordo dos ônibus e trens para monitorar continuamente o trânsito; (iii) detecção de passageiros do transporte público por meio da utilização de cartão inteligente para pagamento de tarifas; (iv) usuários do transporte público aptos a obter informações em tempo real sobre o trânsito em seus telefones móveis; (v) implantação de estacionamentos automatizados para melhorar o aproveitamento dos espaços destinados a esta finalidade; (vi) as cinco cidades utilizam sistemas de tráfego coordenados por sinal, que reduzem o tempo de viagem, o consumo de combustível e ainda o controle de limite de velocidade e da entrada em vias expressas com parquímetro.

Nota-se que estas tecnologias estão relacionadas à melhoria da eficiência dos sistemas de transporte, sendo importantes considerá-las na avaliação de projetos de mobilidade urbana.

Embora Debnath et al. (2014) destaquem Londres de forma positiva quanto ao uso de tecnologias inovadoras nos sistemas de transporte, Hickman, Hall e Banister (2013) apontam que são necessárias mudanças no planejamento do transporte de Londres e o condado de Oxford, abrangendo o território urbano e seus impactos regionais, para que seja alcançado um cenário ideal de mobilidade urbana sustentável. Estas mudanças envolvem grandes investimentos em transporte público, modos não motorizados e baixas emissões veiculares e aludem à necessidade iminente da adoção de padrões eficientes de utilização de recursos enfatizada por Sachs (2012).

\section{CONSIDERAÇÕES FINAIS}

A contribuição das tecnologias inovadoras para a melhoria da mobilidade pode ser traduzida na eficiência com que a população alcança as oportunidades no espaço urbano. Em geral, estas oportunidades significam trabalho, e estudo, relacionadas ao atendimento às necessidades básicas de habitação, segurança, saúde, entre outras que contribuam para a harmonia entre o alcance social e a viabilidade econômica da vida nas cidades.

Aparentemente, o recorte literário deste estudo induz à dissociação entre os gastos em infraestrutura básica e os investimentos em tecnologias inovadoras. É evidente que os resultados positivos das inovações sejam mais nítidos em metrópoles onde os problemas inerentes ao processo de urbanização se resumam 
às questões ambientais relacionadas às emissões de poluentes. Porém, este cenário também está distante da harmonização proposta pelo conceito de desenvolvimento sustentável.

Por outro lado, nos grandes centros urbanos onde já foram implantadas algumas tecnologias inovadoras para controle e monitoramento dos sistemas de transporte, a exemplo de Curitiba/PR, existem dificuldades em resolver as questões relacionadas ao furto dos equipamentos implantados nos corredores de transporte e que serviriam àqueles propósitos. Em um estudo aprofundado desta questão, possivelmente viriam à tona as mazelas sociais relacionadas à ausência das necessidades básicas da população.

Embora novas tecnologias componham uma variável importante no planejamento de sistemas de transporte, não conduzem à fórmula perfeita que resulte na mobilidade urbana sustentável. Ademais, espera-se que estas inovações sejam consideradas não apenas na melhoria das condições de mobilidade já instaladas, mas também nas transformações das relações de trabalho e bem estar social, superando os dilemas entre a preservação de recursos naturais e 0 desenvolvimento econômico.

\section{REFERÊNCIAS}

BOSSEL, H. Indicators for sustainable development: theory, method, applications: a report to the Balaton Group. Winnipeg: IISD, 1999.

COMISSÃO MUNDIAL SOBRE MEIO AMBIENTE E DESENVOLVIMENTO. Nosso Futuro Comum. Rio de Janeiro: Fundação Getúlio Vargas, 1991.

DEBNATH, A. K. et al. A methodological framework for benchmarking smart transport cities. Cities, v. 37, p. 47-56, 2014.

DUARTE, F.; LIBARDI, R.; SÁNCHEZ, K. Introdução à mobilidade urbana. Curitiba: Juruá Editora, 2009.

FERNANDES, V. A racionalização da vida como processo histórico: crítica à racionalidade econômica e ao industrialismo. Cadernos EBAPE.BR (FGV), v. 6, p. 01-20, 2008.

FURTADO, C. Entre o inconformismo e reformismo. Revista de Economia Política, v. 9, n. 4, p. 6-28, out.-dez. 1989.

FURTADO, C. 1920: O mito do desenvolvimento econômico. Rio de Janeiro: Paz e Terra, 1996. 
FURTADO, C. Em busca de novo modelo: reflexões sobre a crise contemporânea. São Paulo: Paz e Terra, 2002.

GASPAR, R.C. A economia política da urbanização contemporânea. Cad. Metrop., São Paulo, v. 13, n. 25, p. 235-256, jan/jun 2011.

HAQUE, M. M.; CHIN, H. C.; DEBNATH, A. K. Sustainable, safe, smart - three key elements of Singapore's evolving transport policies. Transport Policy, v. 27, p. 2031, 2013. doi:10.1016/j.tranpol.2012.11.017.

HICKMAN, R.; HALL, P.; BANISTER, D. Planning more for sustainable mobility. Journal of Transport Geography, v. 33, p. 210-219, 2013.

INSTITUTO BRASILEIRO DE GEOGRAFIA E ESTATÍSTICA. Indicadores de Desenvolvimento Sustentável - Brasil 2010.

JOUMARD, R; NICOLAS, J. P. Transport project assessment methodology within the framework of sustainable development. Ecological Indicators, v. 10, n. 2, p. 136142, 2010.

MAX-NEEF, M. et al. Desarollo a escala humana: conceptos, aplicaciones y reflexiones. Montevideo: Nordan Comunidad, REDES, 1993.

MEADOWS, D. The Limits to Growth. Direitos reservados para língua portuguesa à Editora Perspectiva. São Paulo: 1973.

MEADOWS, D. Indicators and Information Systems for Sustainable

Development: A Report to the Balaton Group. The Sustainability Institute. 1998.

Disponível em: <http://www.iisd.org/pdf/s_ind_2.pdf> Acesso em: 19 jul. 2013.

POLANYI, K. El sustento del hombre. Barcelona: Mondadori, 1994

POLANYI, K. 1886 -1964 A grande transformação: as origens de nossa época Tradução de Fanny Wrobel. 2. ed. Rio de Janeiro: Campus, 2000.

ROMANELLI, C.; ABIKO, A. K. Processo de Metropolização no Brasil. São Paulo: EPUSP, 2011. 34 p. (Texto Técnico da Escola Politécnica da USP, Departamento de Engenharia de Construção Civil, TT/PCC/28).

SACHS, I. Caminhos para o desenvolvimento Sustentável. Rio de janeiro: Garamound, 2000.

SACHS, I.. De volta à mão visível: os desafios da Segunda Cúpula da Terra no Rio de Janeiro. Estudos avançados, São Paulo, v. 26, n. 74, p. 5-20, 2012.

SANTOS, M. A urbanização brasileira. 2. ed. São Paulo: Hucitec, 1994.

SASSEN, S. The global city: London, New York, Tokyo. Nova Jersey: Princeton University Press, 2001. 
SASSEN, S. Territory, authority, rights: from medieval to global assemblages. Nova Jersey: Princeton University Press, 2006.

SASSEN, S. Una sociología de la globalización. Buenos Aires: Katz Editores, 2007.

SEN, A. Desenvolvimento como liberdade. São Paulo: Companhia das Letras, 2000.

SOLOW, R.M. Growth theory: an exposition. London: Oxoford University Press, 2000.

TAVARES, L. P. São José dos Pinhais no contexto da recente industrialização metropolitana: reflexos socioespaciais. Revista Paranaense de Desenvolvimento, Curitiba, n.108, p.33-59, jan./jun. 2005.

VEIGA, J.E. Desenvolvimento sustentável: o desafio do século XXI. Rio de Janeiro: Garamond, 2005.

WEBER, M. A ética protestante e o espírito do capitalismo. São Paulo: Pioneira, 1996. 